\title{
Effect of intravitreal injection of ranibizumab on retinal ganglion cells and microvessels in the early stage of diabetic retinopathy in rats with streptozotocin-induced diabetes
}

\author{
ANG XIAO $^{1,2}$, QIONG ZHOU ${ }^{1}$, YI SHAO ${ }^{1}$ and HUI-FENG ZHONG ${ }^{3}$ \\ ${ }^{1}$ Department of Ophthalmology, The First Affiliated Hospital of Nanchang University, Nanchang, Jiangxi 330006; \\ Departments of ${ }^{2}$ Ophthalmology and ${ }^{3}$ Intensive Care, The First Affiliated Hospital of Gannan Medical University, \\ Ganzhou, Jiangxi 341000, P.R. China
}

Received September 6, 2015; Accepted December 9, 2016

DOI: $10.3892 /$ etm.2017.4431

\begin{abstract}
The aim of the present study was to investigate the effect of intravitreal injection of ranibizumab on retinal ganglion cells and microvessels at the early stage of diabetic retinopathy (DR) in rats with streptozotocin-induced diabetes mellitus (DM). DM was induced by a single intraperitoneal injection of $60 \mathrm{mg} / \mathrm{kg}$ body weight streptozotocin. A total of 80 diabetic rats were randomly assigned to four treatment groups ( $n=20$ in each group) and were treated with an oculus dexter intravitreal injection of ranibizumab. Groups A and $B$ were injected with ranibizumab two and four weeks after DM-induction, respectively, while groups a and b (controls) were injected with phosphate-buffered saline at the same time points. In addition, 20 normal rats were assigned to group $\mathrm{N}$ (blank control; without intraocular injection). Vitreous humors were isolated for vascular endothelial growth factor (VEGF)-A ELISA and retinas were obtained for hematoxylin and eosin staining, periodic acid-Schiff staining and fluorescence imaging techniques at six and eight weeks after the onset of DM. At six and eight weeks, a significantly increased in retinal ganglion cells (RGCs) was observed in group A compared with group a $(\mathrm{P}<0.01)$, and in group $\mathrm{B}$ compared with group $\mathrm{b}(\mathrm{P}<0.01)$. In addition, there was a significant difference in the RGC level between groups A and B at six weeks after DM induction $(\mathrm{P}<0.01)$, but not at eight weeks $(\mathrm{P}>0.05)$. VEGF-A concentrations in rat vitreous humors were significantly lower in groups A and B compared with groups $\mathrm{a}$ and $\mathrm{b}$ at six and eight weeks after DM induction $(\mathrm{P}<0.01)$. Furthermore, the ratio of endotheliocytes to pericytes in groups $\mathrm{A}$ and $\mathrm{B}$ was
\end{abstract}

Correspondence to: Professor Qiong Zhou, Department of Ophthalmology, The First Affiliated Hospital of Nanchang University, 17 Yongwaizheng Street, Nanchang, Jiangxi 330006, P.R. China

E-mail: qiongz-ms@126.com

Key words: diabetic retinopathy, ranibizumab, retinal ganglion cells, type IV collagen, vascular endothelial growth factor A significantly lower compared with groups a and b at six and eight weeks $(\mathrm{P}<0.05)$. Furthermore, it was also demonstrated that type IV collagen-positive strands were not present in group A during the eight-week observation period, which was significantly different from groups a, b and $\mathrm{B}(\mathrm{P}<0.01)$. In conclusion, intravitreal injection of ranibizumab at a very early stage of DR in streptozotocin-induced DM rats slowed the progression of DR by reducing vascular regression or damage and maintaining RGC numbers, as well as reducing VEGF-A concentrations.

\section{Introduction}

Diabetic retinopathy (DR) is a chronic, progressive, vision-threatening disease of the retinal microvasculature, and is one of the predominant factors contributing to blindness, particularly in the working-age population (1-3) Currently, DR affects $\sim 150$ million people worldwide, and the World Health Organization has estimated that this number will double by the year 2025 (4).

The main function of vascular endothelial growth factor (VEGF)-A is to regulate vascular permeability; however, it also has important roles in angiogenesis, vasculogenesis and endothelial cell growth under normal and pathological conditions (5). Pharmacological inhibition of VEGF-A has been demonstrated to be effective at preventing angiogenesis and vascular leakage associated with various eye diseases (6). Since the early stages of DR are asymptomatic, any loss of vision cannot be restored. Laser photocoagulation is effective at slowing down the progression of DR but not at restoring lost vision (7). Furthermore, overall control of blood glucose levels can slow the progression of DR and significantly reduce the risk of DR progression, but fails to prevent or reverse the clinical symptoms of diabetic retinopathy $(7,8)$.

Ranibizumab is a recombinant humanized antibody antigen-binding fragment that neutralizes all known active forms of VEGF-A (9). The tolerability, safety and efficacy of ranibizumab regarding the treatment of diabetic macular edema and age-related macular degeneration have been confirmed (9-14). However, once retinal neovascularization has occurred, the majority of the damage is irreversible (15). 
Therefore, it is more important to prevent retinal neovascularization from developing at the pre-angiogenic stage than to cure it in the post-angiogenic stage (15).

Furthermore, while it is understood that VEGFoverexpression in retinal tissue promotes the development of $\mathrm{DR}$, it is unclear whether reducing VEGF concentrations in the early stages of DR through the early administration of ranibizumab will delay or prevent its progression. Therefore, the aim of the present study was to investigate the effect of an intravitreal injection of ranibizumab on retinal ganglion cells (RGCs) and microvessels in the early stages of DR in rats with streptozotocin (STZ)-induced diabetes mellitus (DM), in order to determine whether ranibizumab may delay the progression of DR.

\section{Materials and methods}

Ethics statement. All experiments were conducted in accordance with the legislation of the Experimental Animal Ethical Committee for Traditional Chinese Medicine (Nanchang, China).

Animals. A total of 100 8-week-old male Sprague-Dawley rats (weight, 220 $\pm 20 \mathrm{~g}$ ) were purchased from the Animal Center of Nanchang University (Nanchang, China). Rats were maintained under a controlled temperature $\left(23 \pm 2^{\circ} \mathrm{C}\right)$, humidity $(50 \%)$ and lighting (12-h light/dark cycle) conditions, and had ad libitum access to sterilized standard laboratory chow and water. Rats were treated in accordance with principles of animal ethics and were anesthetized with an intraperitoneal injection of pentobarbital (40 mg/kg body weight; Sigma-Aldrich; Merck $\mathrm{kGaA}$, Darmstadt, Germany) for the subsequent experiments.

Diabetes induction and experimental groups. DM was induced by a single intraperitoneal injection of $60 \mathrm{mg} / \mathrm{kg}$ body weight STZ (Sigma-Aldrich; Merck kGaA). Rats with blood glucose levels $\geq 13.9 \mathrm{mmol} / 1$ (250 mg/dl) $24 \mathrm{~h}$ after STZ injection were classified as diabetic. A total of 80 diabetic rats were randomly assigned to one of four treatment groups (n=20/group): Groups $\mathrm{A}$ and $\mathrm{B}$ were oculus dexter-injected with $1 \mu \mathrm{l}$ ranibizumab (Novartis, Zurich, Switzerland) (16) at two and four weeks after DM-induction, respectively, while groups a and b (controls) were injected with $1 \mu \mathrm{l}$ sterile phosphate-buffered saline (PBS) at the same time points. An additional 20 normal rats were assigned to group N (blank control; without intraocular injection).

Intraocular ranibizumab administration. Rats received an oculus dexter intravitreal injection of $1 \mu \mathrm{l}$ ranibizumab under anesthesia. Once the corneal reflex was abolished, ranibizumab was injected into the center of the vitreous humor, $0.5-\mathrm{mm}$ posterior to the limbus, using a 5- $\mu 1$ microsyringe (Hamilton, Bonaduz, Switzerland). Injections of $1 \mu \mathrm{l}$ sterile PBS were administered to groups a and $b$. Eyes with evidence of injury to the lens or retina were excluded from the analysis.

Experimental samples. In order to label all blood-circulating vessels, an intravascular perfusion of fluorescent tomato (Lycopersicon esculentum) lectin was used (17). Anesthetized rats were intravenously injected with $500 \mu \mathrm{l}$ fluorescein isothiocyanate-conjugated tomato lectin $(1 \mathrm{mg} / \mathrm{ml}$; Sigma-Aldrich;
Merck kGaA). Tomato lectin binds uniformly to the luminal surface of endothelial cells (18) and labels all blood vessels with an adequate blood supply. At 10 min after injection, rats were first perfused with stroke-physiological saline solution for $10 \mathrm{~min}$ and subsequently, continuously perfused with $4 \%$ paraformaldehyde in PBS through the left ventricle at pressures of $80-120 \mathrm{mmHg}$ for 5-10 min under anesthesia. The vitreous humor and retina were isolated from the eye under an x2.5 anatomic microscope. The vitreous humor was isolated for ELISA and the retina for hematoxylin and eosin (H\&E) staining, periodic acid-Schiff (PAS) staining and fluorescence imaging techniques at six and eight weeks subsequent to induction of DM.

Estimation of VEGF-A in vitreous humor. Isolated vitreous humor was homogenized in $150 \mu \mathrm{l}$ sterile PBS after being frozen at $-80^{\circ} \mathrm{C}$ for $5 \mathrm{~min}$. Levels of VEGF-A protein in the vitreous homogenates were estimated using a rat VEGF-A ELISA kit capable of detecting both VEGF-A isoforms (RayBiotech Inc., Norcross, GA, USA), according to the manufacturer's instructions. The antibodies in the kit have $>95 \%$ cross-reactivity with rat VEGF-A.

$H \& E$-stained retinal preparations. One-third of the retinal tissues were isolated from normal and diabetic rats, and fixed in $4 \%$ paraformaldehyde solution at $20^{\circ} \mathrm{C}$ for $2 \mathrm{~h}$. Samples were subsequently sectioned $(5 \mu \mathrm{m})$, stained with $\mathrm{H} \& \mathrm{E}$ and examined under a light microscope (magnification, x400; Zeiss AG, Oberkochen, Germany) to determine the number of RGCs present in the sample.

PAS-stained retinal preparations. One-third of retinal tissues were isolated from each group and fixed in $4 \%$ paraformaldehyde solution for at $20^{\circ} \mathrm{C} 24 \mathrm{~h}$. Samples were subsequently placed into trypsin fluid for $40 \mathrm{~min}$ at $37^{\circ} \mathrm{C}$, stained with PAS and examined under a light microscope (magnification, $\mathrm{x} 400$; Zeiss $\mathrm{AG}$ ) to calculate the ratio of endotheliocytes to pericytes $(\mathrm{E} / \mathrm{P})$.

Fluorescence imaging techniques for flat retinal preparations. Retinal flat-mounts were processed to visualize the vascular basement membrane by immersing them in marker solutions. Prior to immersion staining, the retinal flat-mounts were incubated for $30 \mathrm{~min}$ at room temperature in 5\% normal bovine serum in PBS containing 0.5\% Triton-X-100 $(0.5 \%$ T-PBS) as a blocking agent. Subsequently, the flat-mounts were immersed overnight at room temperature in a marker solution containing rabbit polyclonal anti-type IV collagen antibody solution (1:300; ab19808; Abcam, Cambridge, UK) for basement membrane (19). Fluorescent goat anti-rabbit immunoglobulin (Ig) G (1:45; BA1105; Wuhan Boster Biological Technology, Ltd., Wuhan, China) was used as a secondary antibody. Subsequent to secondary incubation at $20^{\circ} \mathrm{C}$ for $5 \mathrm{~min}$, the retinal flat-mounts were washed three times in $0.5 \% \mathrm{~T}$-PBS, placed into DAPI for $5 \mathrm{~min}$ and washed an additional three times in $0.5 \%$ T-PBS. The retinal flat-mounts were then mounted on a Vectashield (Wuhan Boster Biological Technology, Ltd.) and analyzed using a Zeiss LSM 710 confocal laser scanning microscope to determine the number of type-IV collagen strands. 
Image processing and statistical analysis. Images were processed using Image-Pro Plus 6.0 (Media Cybernetics Inc., Rockville, MD, USA) and statistical analyses were performed using SPSS version 19.0 (IBM SPSS, Armonk, NY, USA). The five groups (A, B, a, b and N) were compared during the same experimental week using one-way analysis of variance and an independent-samples $t$-test. All data are expressed as mean \pm standard error. $\mathrm{P}<0.05$ was considered to indicate a statistically significant difference.

\section{Results}

Metabolic condition of rats. Blood glucose levels and body weights were measured in each group at various time points (Fig. 1). Significant differences in blood glucose levels were observed between diabetic and normal rats as early as $24 \mathrm{~h}$ subsequent to STZ-administration $(\mathrm{P}<0.01)$. However, there were no significant differences in blood glucose levels or body weights among the diabetic rats at two days, three days, six weeks or eight weeks after STZ-injection $(P>0.05)$. There were no significant differences in body weight between diabetic and normal rats three days after induction of DM $(\mathrm{P}>0.05)$; however, there were significant differences six and eight weeks after induction $(\mathrm{P}<0.01)$.

Retinal H\&E staining. Morphological changes in the nerve fiber layer and the outer nuclear layer were assessed six and eight weeks subsequent to the onset of DM, and the number of RGCs was counted (Fig. 2). The number of RGCs and the retinal structure in group $\mathrm{N}$ at six and eight weeks after experiment initiation are presented in Fig. 2. Compared with group N (28.87 \pm 0.92$)$, significant differences in RGC numbers were observed in group A $(20.73 \pm 0.96)$, group B (19.53 \pm 0.99$)$, group a $(10.60 \pm 0.83)$ and group b $(11.53 \pm 0.99)$ six weeks after the onset of DM (all $\mathrm{P}<0.01$ ); however, the number of RGCs significantly decreased between six and eight weeks in groups $\mathrm{a}$ and $\mathrm{b}$ (both $\mathrm{P}<0.01)$. Groups $\mathrm{A}$ and $\mathrm{B}$, however, exhibited no difference in the number of RGCs at eight weeks (19.80 \pm 1.01 and $19.47 \pm 0.99$, respectively) compared with at six weeks (both $\mathrm{P}>0.05$ ). At six and eight weeks, the number of RGCs in groups A and B was significantly different from that in groups a and $\mathrm{b}(\mathrm{P}<0.01)$. Furthermore, a significant difference was observed in the number of RGCs between groups A and B after six weeks $(\mathrm{P}<0.05)$; however, a significant difference was not observed after eight weeks ( $P>0.05)$. There was no significant difference in the number of RGCs in groups a and b at six or eight weeks ( $\mathrm{P}>0.05)$.

New vessels were observed in the retinas of groups $a$ and $b$ at the junction between the RGC layer and the inner plexiform layer, and the junction between the inner nuclear layer and the outer plexiform layer, at both six and eight weeks (Fig. 2). The number of neuronal cells in the inner and outer nuclear layers of the retina did not significantly differ in any of the five groups between six and eight weeks.

Retinal PAS staining. In the diabetes groups, the nuclei of endotheliocytes were oval and the dye was pale, while the nuclei of pericytes were circular and the dye was darker in color compared to the endotheliocytes (Fig. 3A-D). No abnormalities were observed in PAS-stained retinal vessels from group N (Fig. 3E). Compared with group N (2.65 \pm 0.06$)$, the $\mathrm{E} / \mathrm{P}$ ratio was significantly increased in groups a $(3.78 \pm 0.09)$, b $(3.76 \pm 0.03)$ and $\mathrm{B}(3.67 \pm 0.08$; all $\mathrm{P}<0.01)$ six weeks subsequent to induction of DM, however, the same was not observed in group A $(2.64 \pm 0.04 ; \mathrm{P}>0.05$; Fig. 3F). The E/P ratio in group $\mathrm{A}$ was significantly lower than that in groups $\mathrm{a}$, $\mathrm{b}$ and $\mathrm{B}$ at six weeks, and was significantly different between group $\mathrm{B}$ and groups a and $\mathrm{b}(\mathrm{P}<0.05)$. Significant differences were observed between groups $\mathrm{N}(2.66 \pm 0.05)$, a $(3.97 \pm 0.06)$, b (4.00 \pm 0.07$)$ and $\mathrm{A}(3.14 \pm 0.12)$ at eight weeks (all $\mathrm{P}<0.01)$; however, there was no significant difference between groups $\mathrm{N}$ and $\mathrm{B}(2.67 \pm 0.04 ; \mathrm{P}>0.05)$, in which the E/P ratio significantly declined compared with the other diabetes groups (all $\mathrm{P}<0.01$; Fig. 3F). Furthermore, a significant difference was exhibited between group $\mathrm{A}$ and groups $\mathrm{a}$ and $\mathrm{b}$ at eight weeks (both $\mathrm{P}<0.01$ ). Acellular capillaries were observed in groups a and $b$ at eight weeks, but not six weeks, after the induction of DM (Fig. 3).

Estimation of VEGF-A in vitreous humor. A rat VEGF-A ELISA kit was utilized to detect the concentration of VEGF-A in rat vitreous humor. Six weeks subsequent to DM induction, the VEGF-A concentrations in groups $\mathrm{N}, \mathrm{A}$, $\mathrm{B}$, $\mathrm{a}$ and $\mathrm{b}$ were $9.67 \pm 0.90,10.10 \pm 0.52,9.44 \pm 1.27,17.62 \pm 4.43$ and $17.73 \pm 3.70 \mathrm{pg} / \mathrm{ml}$, respectively (Fig. 4). A significantly lower VEGF-A concentration was observed in groups A and $\mathrm{B}$ at six weeks compared with groups a and b (both $\mathrm{P}<0.01$ ); however, no significant difference was exhibited in groups $\mathrm{A}$ or $\mathrm{B}$ compared with group $\mathrm{N}$ (both $\mathrm{P}>0.05$ ). At eight weeks, the VEGF-A concentration in groups $\mathrm{N}, \mathrm{A}, \mathrm{B}$, $a$ and $b$ was $9.51 \pm 0.81,14.33 \pm 0.79,10.24 \pm 0.51,19.50 \pm 4.15$ and $20.06 \pm 4.19 \mathrm{pg} / \mathrm{ml}$, respectively. The VEGF-A concentration in group A was significantly higher compared with that of groups $\mathrm{N}$ or $\mathrm{B}$ at eight weeks (both $\mathrm{P}<0.01$ ); however, it was significantly lower compared with that of groups a and b $(\mathrm{P}<0.05)$. No significant difference was exhibited between groups $\mathrm{B}$ and $\mathrm{N}(\mathrm{P}>0.05)$; however, these groups had significantly lower VEGF-A concentrations compared with groups $\mathrm{a}$ and $\mathrm{b}$ at eight weeks (all $\mathrm{P}<0.01$ ).

Immunohistochemical verification of retinal vascular changes. Using the retinal flat-mounts stained with intravenously-injected tomato lectin and type IV collagen antibody, it was observed that a significantly increased number of vessels in groups $a$ and $b$ were bridged with type IV collagen-positive strands (type $\mathrm{IV}_{+}$) compared with group $\mathrm{N}$, where there were no type IV collagen-positive strands detected $(\mathrm{P}<0.01$; Fig. 5). Vascular permeability (thin arrows, Fig. 5) was observed in the diabetic retinas of these rats six weeks after STZ administration, compared with no such permeability in group N. Furthermore, no significant difference was observed between the number of type $\mathrm{IV}_{+}$strands at both six and eight weeks $(\mathrm{P}>0.05)$, and vascular permeability increased in groups a and $\mathrm{b}$ at eight weeks after DM induction, when vascular buds were observed (thick arrows, Fig. 5A-D). The number of type $\mathrm{IV}_{+}$strands in groups a, b and B were $14.73 \pm 1.03,14.80 \pm 0.94$ and $6.87 \pm 0.99$, respectively, at six weeks, compared with $14.33 \pm 0.98,15.67 \pm 0.90$ and $2.20 \pm 0.77$, respectively, at eight weeks (Fig. 5F).

Only the rats in groups a and b exhibited a significant increase in the number of type $\mathrm{IV}_{+}$acellular strands in 

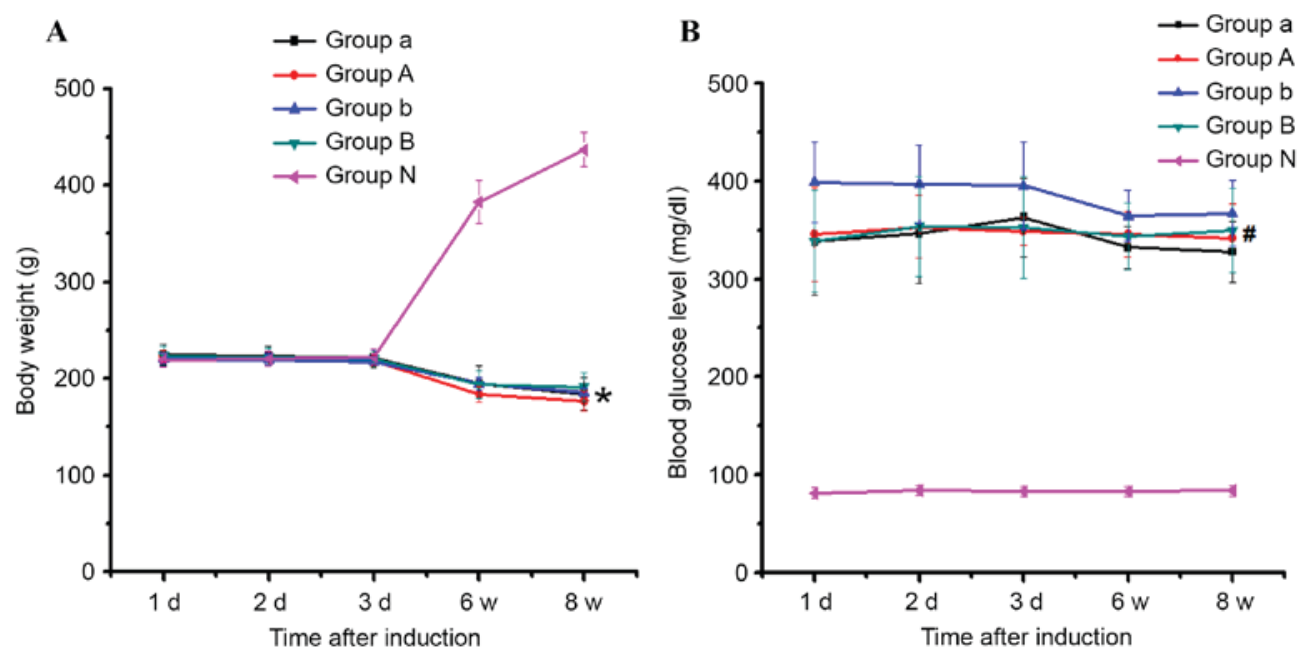

Figure 1. (A) Body weights and (B) blood glucose levels of the animals used in the present study. Values are presented as the mean \pm standard error of the mean. ${ }^{*} \mathrm{P}<0.01$ for all diabetes groups vs. group $\mathrm{N}$ at six and eight weeks; ${ }^{*} \mathrm{P}<0.01$ for all diabetes groups vs. group $\mathrm{N}$ at all time points.

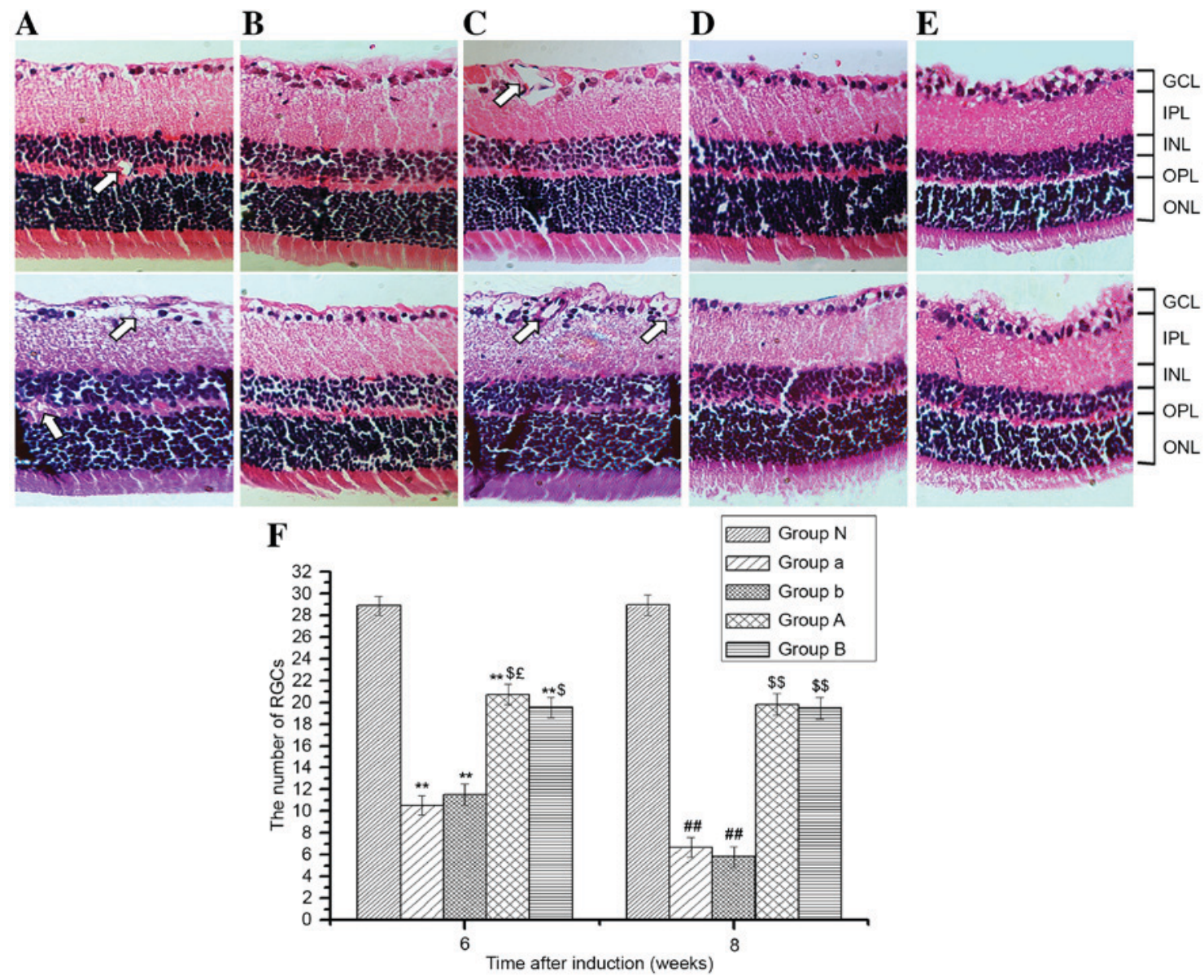

Figure 2. Hematoxylin and eosin staining of retinal tissues in normal and diabetes mellitus rats (magnification, x400). RGCs were counted and neovascularization was observed in diabetic rats from group a at (A, upper) six and (A, lower) eight weeks; from group A at (B, upper) six and (B, lower) eight weeks; from group b at (C, upper) six and (C, lower) eight weeks; from group B at (D, upper) six and (D, lower) eight weeks; and normal rats at (E, upper) six and (E, lower) eight weeks. (F) Number of RGCs from each group at six and eight weeks after diabetes induction. ${ }^{* *} \mathrm{P}<0.01$ vs. $\mathrm{N}$ group at six weeks; ${ }^{\# \#} \mathrm{P}<0.01 \mathrm{vs}$. the same group at six weeks; ${ }^{\$} \mathrm{P}<0.01$ vs. groups a and b at six weeks; ${ }^{\$ \$} \mathrm{P}<0.01$ vs. groups a and b at eight weeks; ${ }^{{ }^{\mathrm{P}}} \mathrm{P}<0.05$ vs. group B at six weeks. White arrows indicate new vessels. RGCs, retinal ganglion cells; GCL, ganglion cell layer; INL, inner nuclear layer; IPL, inner plexiform layer; ONL, outer nuclear layer; OPL, outer plexiform layer.

the peripheral retinas, compared with groups $\mathrm{A}, \mathrm{B}$ and $\mathrm{N}$. Type $\mathrm{IV}_{+}$strands, vascular buds, and vascular permeability were not observed in group A rats at six or eight weeks after
DM induction. In addition, the number of type $\mathrm{IV}_{+}$strands in group B significantly decreased between six and eight weeks (Fig. 5), and group B rats exhibited significantly fewer type IV ${ }_{+}$ 

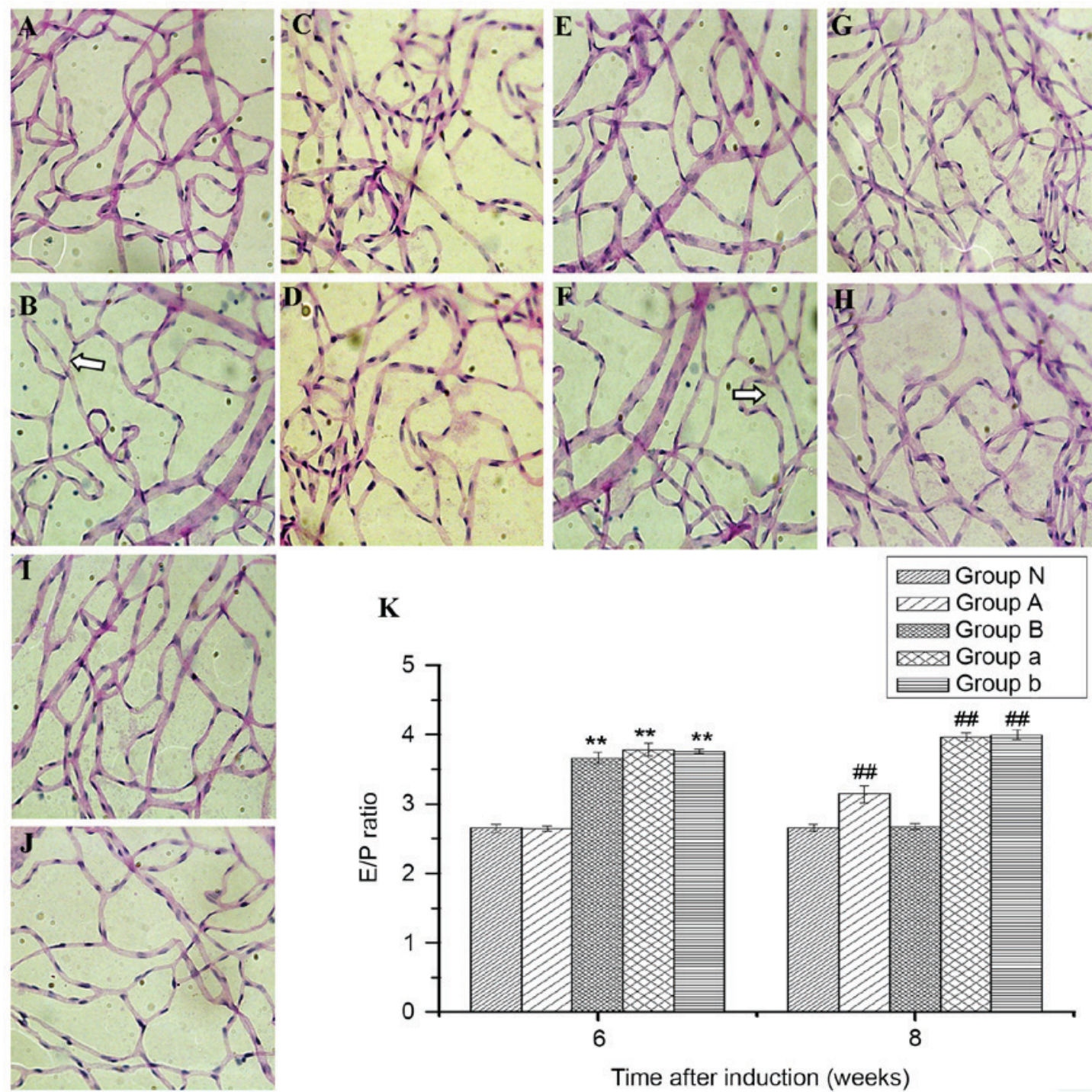

Time after induction (weeks)

Figure 3. Periodic acid-Schiff staining of retinal tissues in normal and diabetes mellitus rats to observe changes in the ratio of endotheliocytes to pericytes and whether there were acellular capillaries (magnification, $\mathrm{x} 400$ ). Diabetic rats from group a at (A) six and (B) eight weeks; from group A at (C) six and (D) eight weeks; from group b at (E) six and (F) eight weeks; from group B at $(\mathrm{G})$ six and $(\mathrm{H})$ eight weeks; and from normal rats at (I) six and (J) eight weeks. (K) The ratio of endotheliocytes to pericytes at six and eight weeks after diabetes induction. White arrows indicate acellular capillaries. Bars indicate $95 \%$ confidence intervals. ${ }^{* *} \mathrm{P}<0.01$ vs. groups $\mathrm{N}$ and $\mathrm{A}$ at six weeks and ${ }^{\# \#} \mathrm{P}<0.01$ vs. groups $\mathrm{N}$ and $\mathrm{B}$ at eight weeks. $\mathrm{E} / \mathrm{P}$, respectively, ratio of endotheliocytes to pericytes.

strands compared with those in groups a and $\mathrm{b}$ at both six and eight weeks (all $\mathrm{P}<0.01$ ). No vascular permeability or vascular buds were observed in group B.

\section{Discussion}

DR is one of the most common and severe microvascular complications of diabetes, resulting in blindness in middle age. The most common treatments for DR include retinal laser photocoagulation, intravitreal injection of triamcinolone acetonide or ranibizumab and vitrectomy (20). These can rescue some retinal function, however, they do not improve visual acuity. The damage caused by DR is irreversible and the risks of vision loss and blindness are high; therefore, prevention is more important than treatment.

In the present study, the numbers of retinal RGCs were considerably decreased at both six and eight weeks following the development of STZ-induced DM in rats. This finding may be an extension of existing research. RGCs are a major component of the optic nerves and their loss can result in degenerative retinal diseases, including DR and glaucoma, and RGC injury severely impairs vision and can even result in blindness (21). Previous work has demonstrated that increased RGC apoptosis occurs as early as four weeks after the onset of DM. This early neuronal dysfunction may result in cell loss $(22,23)$. In the present study, the early decrease in RGC function was the only neuronal deficit observed at four weeks, and this is consistent with previous reports showing that other deficits occur later $(24,25)$ In addition, RGC numbers have previously been found to be reduced from six weeks $(26,27)$, whereas thinning of the inner and outer nuclear layers has been observed only after ten weeks of hyperglycemia (27). Although the molecular mechanisms responsible for the development of other structural abnormalities or decreased cells are not yet fully understood, it has been hypothesized that inflammation, oxidative stress or exposure to advanced glycation end-products may contribute 
to retinal pathologies, including RGC loss (27). Various detrimental factors, including hypoxia, excitotoxicity and oxidative stress, induce RGC apoptosis $(28,29)$; therefore, oxidative stress in the progression of DR may directly damage RGCs and induce cell apoptosis (30).

In the present study, rats with STZ-induced diabetes that were not treated with ranibizumab (groups a and b) exhibited decreased pericyte numbers in the microvasculature and an increased $\mathrm{E} / \mathrm{P}$ ratio. The histopathological findings of $\mathrm{DR}$ are thickening of the capillary basement membrane, loss of pericytes and the development of acellular and occluded capillaries (31). DR is also recognized as a microangiopathy associated with DM, characterized by the breakdown of the blood-retinal barrier (31). The loss of pericytes in the retinal microvasculature was observed in early studies of patients with diabetes (32); however, the mechanism responsible for this loss of pericytes in the early stages of DR is unclear. Using immunohistochemical staining, researchers have reported that pericytes in the retinal capillaries contain aldose reductase, indicating that the mechanism for loss of pericytes may be related to the sorbitol pathway (33). However, other researchers have not demonstrated the same results. Two research groups observed no immune activity of aldose reductase in rat and dog retinal microvasculature $(34,35)$. Furthermore, one study indicated that hyperglycemia or galactosemia result in abnormal secretion or function of the B chain of platelet-derived growth factor-B, which may selectively affect the activity of pericytes and lead to their apoptosis (36). The loss of pericytes in the microvasculature would result in an increased $\mathrm{E} / \mathrm{P}$ ratio.

Notably, in the present study, histopathology demonstrated that in untreated rats with STZ-induced diabetes (groups a and b), new vessels appeared in the retina at the junctions between the RGC layer and the inner plexiform layer, and between the inner nuclear layer and the outer plexiform layer at six and eight weeks, respectively, subsequent to DM induction. Moreover, the present study demonstrated that many vessels were bridged by type $\mathrm{IV}_{+}$collagen strands in the untreated rats, and that vascular permeability was observed by week six of the experiment. At eight weeks after DM induction, in groups $a$ and $b$, the number of type $\mathrm{IV}_{+}$strands decreased, vascular permeability increased and vascular buds were observed. This may represent a hallmark of angiogenesis, which would result in retinal neovascularization in DR. Currently, VEGF-A, a diffusible cytokine that promotes angiogenesis and vascular permeability, has been implicated as an important factor promoting neovascularization $(14,37)$. Previous studies have reported that VEGF expression was higher in diabetic rats than in normal rats at eight days (38), and reached a peak that was significantly higher in the diabetic rats compared with normal rats at four weeks $(19,39)$. In addition, the overproduction of VEGF is associated with altered angiogenesis and increases in the permeability of retinal capillaries, resulting in retinal dysfunction (40-42). According to these studies, the presence of new vessels and vascular buds may be inevitable, and the increasing vascular permeability appears to be a natural development of the disease process. One study reported that one of the earliest morphological changes exhibited in the retinal vasculature after DM induction was an increase in the number of lectin-negative and type $\mathrm{IV}_{+}$collagen strands containing no cellular elements and lacking any signs of

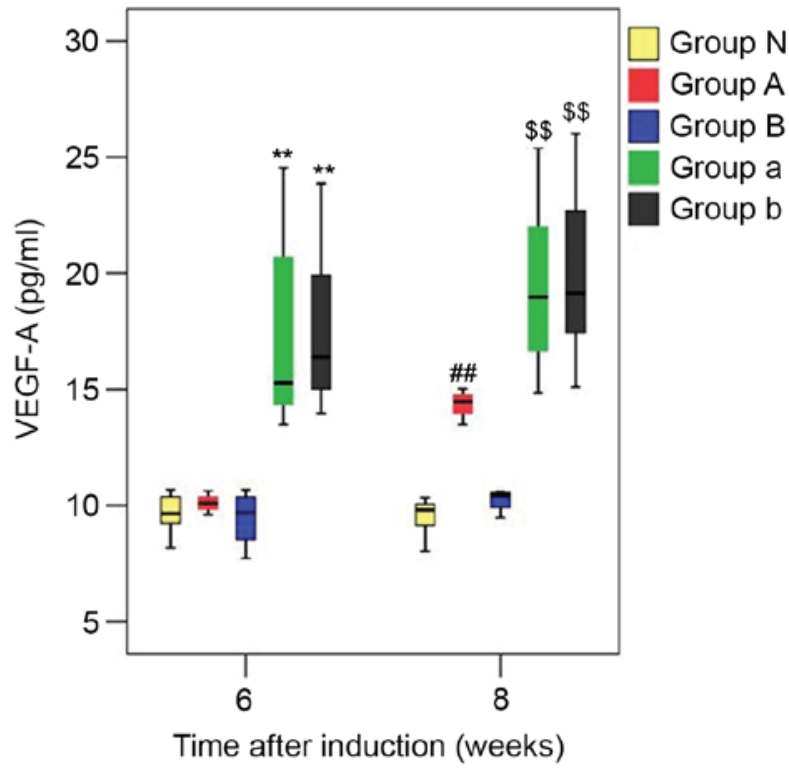

Figure 4. Concentration of VEGF-A in vitreous humor at six and eight weeks after diabetes induction. Filled bars indicate ranges. Horizontal lines indicate standard errors. Vertical lines indicate confidence intervals. ${ }^{* *} \mathrm{P}<0.01$ vs. groups $\mathrm{N}, \mathrm{A}$ and $\mathrm{B}$ at six weeks; ${ }^{\#} \mathrm{P}<0.01$ vs. groups $\mathrm{N}$ and $\mathrm{B}$ at eight weeks; ${ }^{\$} \mathrm{P}>0.05$ vs. groups $\mathrm{A}, \mathrm{N}$ and $\mathrm{B}$ at eight weeks. VEGF-A, vascular endothelial growth factor-A.

endothelial proliferation as early as one and four weeks subsequent to STZ administration (19). The type $\mathrm{IV}_{+}$strands suggest a possible association between vascular regression and the very early stages of DM, as reported in a study by Zhang et al (43). Inai et al (44) demonstrated that vascular regression may also represent structurally collapsed or hollow vessels with no blood flow, resulting in structures called 'vascular ghosts'. Furthermore, during vessel regression, type IV collagen may be able to persist as a remnant among vascular basement membrane components. The basement membrane is an essential part of the blood-retinal barrier. It appears that DM induces the regression of endothelial cells, and that only the basement membrane remains in situ, resulting in changes to these regressing vessels.

In the present study, diabetic rats treated with ranibizumab at either two or four weeks subsequent to DM induction (groups A and B, respectively) exhibited significant decreases in the number of type $\mathrm{IV}_{+}$acellular strands in the peripheral retina and in the E/P ratio at six and eight weeks, with levels decreasing to similar levels to those in non-diabetic control rats. In addition, no new vessels, vascular permeability or vascular buds were observed in the ranibizumab-treated rats, and the decreases in RGC levels and VEGF-A concentrations in the vitreous humor were lower than in diabetic rats administered PBS at six and eight weeks. Intravitreal injection of ranibizumab was more effective in rats treated at two weeks than those treated at four weeks. These findings suggest that intravitreal injection of ranibizumab may protect against vascular damage/regression, RGC loss and angiogenesis, and that it may be more efficacious when administered at two weeks rather than four weeks.

It is widely understood that VEGF has a pivotal role in the growth of abnormal blood vessels, resulting in abnormal 


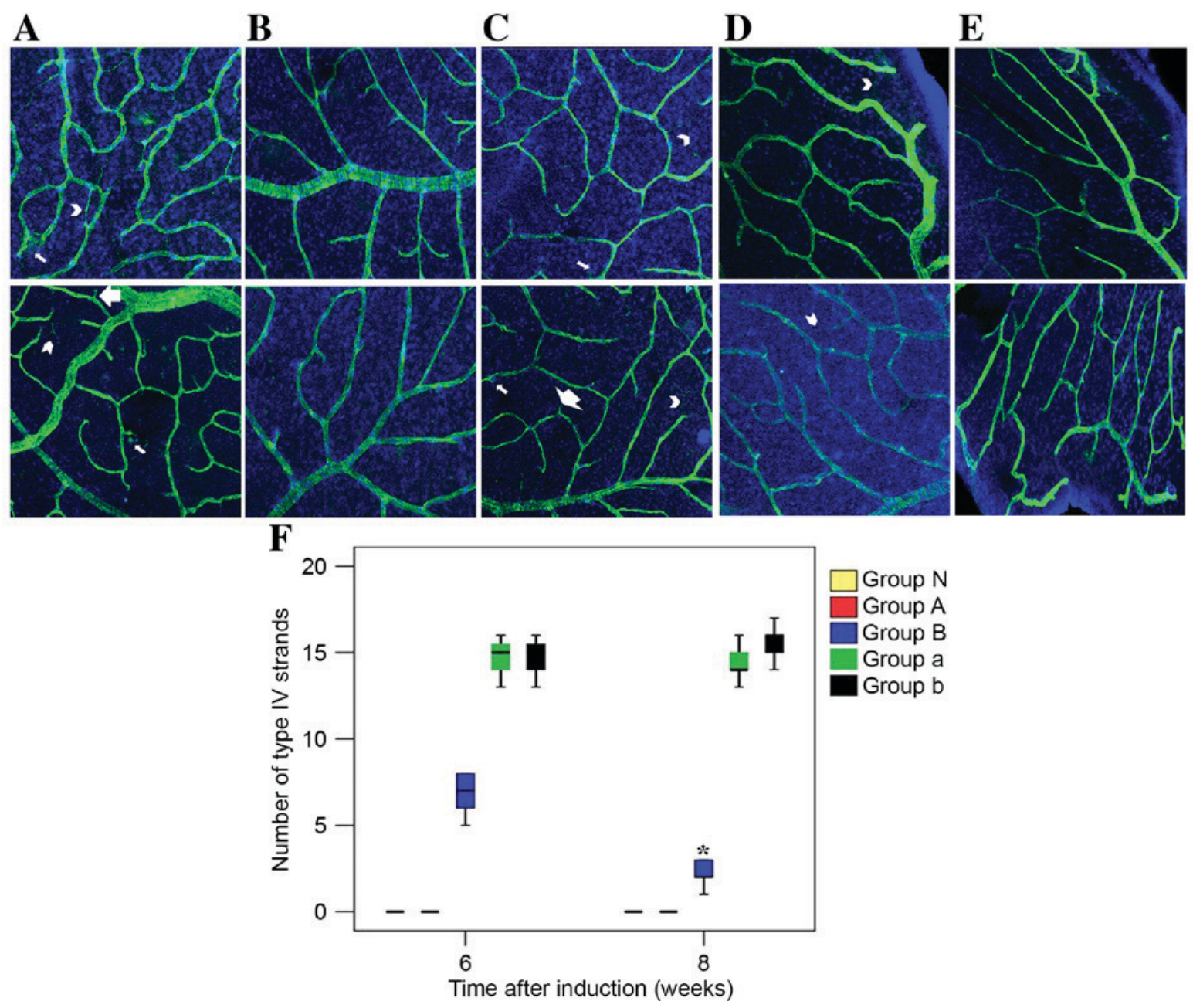

Figure 5. Immunohistochemical imaging of retinal tissues in normal rats to count the number of type IV collagen-positive strands and to observe vascular permeability and vascular buds (magnification, x100). Diabetic rats from group a at (A, upper) six and (A, lower) eight weeks; from group A at (B, upper) six and (B, lower) eight weeks; from group b at (C, upper) six and (C, lower) eight weeks; from group B at (D, upper) six and (D, lower) eight weeks; and from normal rats at (E, upper) six and at (E, lower) eight weeks. (F) Number of type IV collagen-positive strands at six and eight weeks after the induction of diabetes. The number of type IV collagen-positive strands in groups $\mathrm{N}$ and A was zero, therefore they show as blank in the graph. Arrowheads indicate type IV collagen-positive strands. Thin arrows indicate vascular permeability. Thick arrows indicate vascular buds. Filled bars indicate ranges. Horizontal lines indicate standard error. Vertical lines indicate confidence intervals. "P<0.01 vs. same group at six weeks.

hyperplasia of retinal neovascularization (45-47); therefore, the timely inhibition of VEGF may halt disease progression (48). In addition, prospective randomized clinical trials have demonstrated that VEGF inhibitors are effective at treating retinal vascular diseases $(49,50)$. Ranibizumab can bind and neutralize VEGF, particularly VEGF-A, with high affinity (7). In the present study, an intravitreal injection of ranibizumab at two and four weeks subsequent to DM induction in rats resulted in downregulation of VEGF. DM upregulates various proinflammatory mediators (including intercellular adhesion molecule-1, VEGF, nuclear factor- $\mathrm{kB}$, inducible nitric oxide synthase and transforming growth factor- $\beta$ ) in the retina, and localized inflammatory processes have a role in the development of DR $(51,52)$. Increasing evidence suggests that the involvement of inflammatory processes, including cytokine upregulation and leukocyte infiltration, have resulted in DR being classified as an inflammatory disease (53). An inflammatory response and leukocyte recruitment could be considered important components of retinal neuronal death $(54,55)$.
Moreover, type $\mathrm{IV}_{+}$acellular strands have been reported in the retinal vasculature of Sprague-Dawley rats shortly (one week) after treatment with high concentrations of $\mathrm{N}$-methyl-D-aspartate (NMDA) (56). Type $\mathrm{IV}_{+}$acellular strands may have arisen as a result of vessel regression caused by an NMDA signaling disorder, and neuronal cells may have a role in maintaining the normal structure and function of the vasculature in the retina through the production/release of growth factors and trophic factors for vascular cells (56), such as RGC expression of VEGF (57). VEGF has been demonstrated to have a key function in retinal development and the survival of retinal neurons following ischemia/reperfusion injury (58). However, overproduction of VEGF may alter the pro-survival signaling pathway of VEGF in retinal endothelial cells, as well as affect the survival of neuronal cells (59). In the present study, ranibizumab specifically bound to and neutralized VEGF, which may have contributed to preventing angiogenesis and the permeability of the retinal capillary, and also may have balanced the VEGF level in the vitreous humor. Therefore, new vessels and vascular buds were not 
formed, and the migration of various proinflammatory mediators or inflammatory factors, produced by the inflammatory response, and leukocyte recruitment may have been markedly decreased.

The number of RGCs in the ranibizumab-treated groups of the present study improved, unlike in the untreated groups that exhibited a continuous decrease in the number of RGCs after the induction of DM. As neuronal cells, such as the RGCs present in the inner retina, function to maintain the vascular structure via expression of VEGF in the rat retina (60), the increased number of RGSs after ranibizumab treatment may account for the absence of type $\mathrm{IV}_{+}$acellular strands in group A, and may have resulted in the degradation of type $\mathrm{IV}_{+}$acellular strands in group B. Intravitreal injection of ranibizumab two weeks after induction of DM may balance the concentration of VEGF-A in the vitreous humor, which may prevent retinal vascular injury caused by VEGF-A, maintain the E/P ratio and reduce the apoptosis of RGCs and, thereby, help to delay the progression of DR. In the present study, the retinal vessels were damaged and the number of RGCs decreased four weeks after the onset of DM; therefore, the intravitreal injection of ranibizumab four weeks after DM induction downregulated VEGF-A and also limited any further damage caused by its overexpression, which would delay the progression of DR. This suggests that ranibizumab may be more effective when given two weeks after DM induction, rather than at four weeks, by limiting the damage caused by VEGF-A as early as possible. However, the development of DR is a complicated process that is influenced by multiple factors and further investigation may provide novel insights into treatments for this disease at its early stage.

In conclusion, it has been demonstrated that a single intravitreal injection of ranibizumab at a very early stage of DR in rats with STZ-induced DM slowed the progression of DR by reducing vascular regression/damage and maintaining RGC numbers. Furthermore, ranibizumab appears to be more effective when injected at two weeks post-DM induction, compared with four weeks. The results of the present study suggest that further investigation into protection against DR progression through the use of anti-VEGF drugs at an early stage is required.

\section{Acknowledgements}

The present study was supported by: The National Natural Science Foundation of China (grant nos. 81460092, 81160118 and 81400372); Clinical Medicine Research Special-purpose Foundation of China (grant no. L2012052); Jiangxi Province Voyage Project (grant no. 2014022); Jiangxi province Degree and Postgraduate Education Reform Project (grant no. 2015); Science and Technology Platform Construction Project of Jiangxi Province (grant no. 2013116); Youth Science Foundation of Jiangxi Province (grant no. 20151BAB215016); Technology and Science Foundation of Jiangxi Province (grant no. 20151BBG70223); Jiangxi Province Education Department Scientific Research Foundation (grant no. GJJ14170); Health Development Planning Commission Science Foundation of Jiangxi Province (grant no. 20155154); and Scholar Project of Ganjiang River (2015).

\section{References}

1. Fong DS, Aiello L, Gardner TW, Blankenship G, Cavallerano JD, Ferris FL III and Klein R; American Diabetes Association: Diabetic retinopathy. Diabetes Care 26: 226-229, 2003.

2. Singh R, Ramasamy K, Abraham C, Gupta V and Gupta A: Diabetic retinopathy: An update. Indian J Ophthalmol 56: 178-188, 2008.

3. Baharivand N, Zarghami N, Panahi F, Dokht Ghafari MY, Mahdavi Fard A and Mohajeri A: Relationship between vitreous and serum vascular endothelial growth factor levels, control of diabetes and microalbuminuria in proliferative diabetic retinopathy. Clin Ophthalmol 6: 185-191, 2012.

4. Pascolini D and Mariotti SP: Global estimates of visual impairment: 2010. Br J Ophthalmol 96: 614-618, 2012.

5. Ferrara $\mathrm{N}$ and Davis-Smyth T: The biology of vascular endothelial growth factor. Endocr Rev 18: 4-25, 1997.

6. Papadopoulos N, Martin J, Ruan Q, Rafique A, Rosconi MP, Shi E, Pyles EA, Yancopoulos GD, Stahl N and Wiegand SJ: Binding and neutralization of vascular endothelial growth factor (VEGF) and related ligands by VEGF Trap, ranibizumab and bevacizumab. Angiogenesis 15: 171-185, 2012.

7. The effect of intensive treatment of diabetes on the development and progression of long-term complications in insulin-dependent diabetes mellitus. The Diabetes Control and Complications Trial Research Group. N Engl J Med 329: 977-986, 1993.

8. Ohkubo Y, Kishikawa H, Araki E, Miyata T, Isami S, Motoyoshi S, Kojima Y, Furuyoshi N and Shichiri M: Intensive insulin therapy prevents the progression of diabetic microvascular complications in Japanese patients with non-insulin-dependent diabetes mellitus: A randomized prospective 6-year study. Diabetes Res Clin Pract 28: 103-117, 1995.

9. Fong AH and Lai TY: Long-term effectiveness of ranibizumab for age-related macular degeneration and diabetic macular edema. Clin Interv Aging 8: 467-483, 2013.

10. Holz FG, Bandello F, Gillies M, Mitchell P, Osborne A, Sheidow T, Souied E and Figueroa MS; LUMINOUS Steering Committee: Safety of ranibizumab in routine clinical practice: 1-year retrospective pooled analysis of four European neovascular AMD registries within the LUMINOUS programme. Br J Ophthalmol 97: 1161-1167, 2013.

11. Schmucker C, Ehlken C, Agostini HT, Antes G, Ruecker G, Lelgemann M and Loke YK: A safety review and meta-analyses of bevacizumab and ranibizumab: Off-label versus goldstandard. PLoS One 7: e42701, 2012.

12. Evoy KE and Abel SR: Ranibizumab: The first vascular endothelial growth factor inhibitor approved for the treatment of diabetic macular edema. Ann Pharmacother 47: 811-818, 2013.

13. Brown DM, Kaiser PK, Michels M, Soubrane G, Heier JS, Kim RY, Sy JP and Schneider S; ANCHOR Study Group: Ranibizumab versus verteporfin for neovascular age-related macular degeneration. N Engl J Med 355: 1432-1444, 2006.

14. Rosenfeld PJ, Brown DM, Heier JS, Boyer DS, Kaiser PK, Chung CY and Kim RY; MARINA Study Group: Ranibizumab for neovascular age-related macular degeneration. N Engl J Med 355: 1419-1431, 2006.

15. Du ZJ, Kamei M, Suzuki M, Tano Y, Wang BR and Hui YN: Coordinated expression of Ets-1, pERK1/2, and VEGF in retina of streptozotocin-induced diabetic rats. Ophthalmic Res 39: 224-231, 2007.

16. Cloutier F, Lawrence M, Goody R, Lamoureux S, Al-Mahmood S, Colin S, Ferry A, Conduzorgues JP, Hadri A, Cursiefen $\mathrm{C}$, et al: Antiangiogenic activity of aganirsen in nonhuman primate and rodent models of retinal neovascular disease after topical administration. Invest Ophthalmol Vis Sci 53: 1195-1203, 2012.

17. Ezaki T, Baluk P, Thurston G, La Barbara A, Woo C and McDonald DM: Time course of endothelial cell proliferation and microvascular remodeling in chronic inflammation. Am J Pathol 158: 2043-2055, 2001.

18. Thurston G, Baluk P, Hirata A and McDonald DM: Permeability-related changes revealed at endothelial cell borders in inflamed venules by lectin binding. Am J Physiol 271: H2547-H2562, 1996.

19. Mitsuhashi J, Morikawa S, Shimizu K, Ezaki T, Yasuda Y and Hori S: Intravitreal injection of erythropoietin protects against retinal vascular regression at the early stage of diabetic retinopathy in streptozotocin-induced diabetic rats. Exp Eye Res 106: 64-73, 2013. 
20. Kollias AN and Ulbig MW: Diabetic retinopathy: Early diagnosis and effective treatment. Dtsch Arztebl Int 107: 75-84, 2010.

21. Koriyama Y, Ohno M, Kimura T and Kato S: Neuroprotective effects of 5-S-GAD against oxidative stress-induced apoptosis in RGC-5 cells. Brain Res 1296: 187-195, 2009.

22. Barber AJ, Lieth E, Khin SA, Antonetti DA, Buchanan AG and Gardner TW: Neural apoptosis in the retina during experimental and human diabetes. Early onset and effect of insulin. J Clin Invest 102: 783-791, 1998.

23. El-Remessy AB, Al-Shabrawey M, Khalifa Y, Tsai NT, Caldwell RB and Liou GI: Neuroprotective and blood-retinal barrier-preserving effects of cannabidiol in experimental diabetes. Am J Pathol 168: 235-244, 2006.

24. Bui BV, Loeliger M, Thomas M, Vingrys AJ, Rees SM, Nguyen CT, He Z and Tolcos M: Investigating structural and biochemical correlates of ganglion cell dysfunction in streptozotocin-induced diabetic rats. Exp Eye Res 88: 1076-1083, 2009.

25. Kern TS and Barber AJ: Retinal ganglion cells in diabetes. J Physiol 586: 4401-4408, 2008.

26. Martin PM, Roon P, Van Ells TK, Ganapathy V and Smith SB: Death of retinal neurons in streptozotocin-induced diabetic mice. Invest Ophthalmol Vis Sci 45: 3330-3336, 2004.

27. Yang Y, Mao D, Chen X, Zhao L, Tian Q, Liu C and Zhou BL: Decrease in retinal neuronal cells in streptozotocin-induced diabetic mice. Mol Vis 18: 1411-1420, 2012

28. Charles I, Khalyfa A, Kumar DM, Krishnamoorthy RR, Roque RS, Cooper N and Agarwal N: Serum deprivation induces apoptotic cell death of transformed rat retinal ganglion cells via mitochondrial signaling pathways. Invest Ophthalmol Vis Sci 46: 1330-1338, 2005.

29. Tezel G: Oxidative stress in glaucomatous neurodegeneration: Mechanisms and consequences. Prog Retin Eye Res 25: 490-513, 2006.

30. Galetović D, Bojić L, Bućan K, Karlica D, Lesin M and Znaor L: The role of oxidative stress after retinal laser photocoagulation in nonproliferative diabetic retinopathy. Coll Antropol 35: 835-840, 2011.

31. De La Cruz JP, González-Correa JA, Guerrero A and de la Cuesta FS: Pharmacological approach to diabetic retinopathy. Diabetes Metab Res Rev 20: 91-113, 2004.

32. Kuwabara T and Cogan DG: Retinal vascular patterns: VI. Mural cells of the retinal capillaries. Arch Ophthalmol 69: 492-502, 1963.

33. Akagi Y, Kador PF, Kuwabara T and Kinoshita JH: Aldose reductase localization in human retinal mural cells. Invest Ophthalmol Vis Sci 24: 1516-1519, 1983.

34. Kern TS and Engerman RL: Distribution of aldose reductase in ocular tissues. Exp Eye Res 33: 175-182, 1981.

35. Kern TS and Engerman RL: Immunohistochemical distribution of aldose reductase. Histochem J 14: 507-515, 1982.

36. Mizutani M, Kern TS and Lorenzi M: Accelerated death of retinal microvascular cells in human and experimental diabetic retinopathy. J Clin Invest 97: 2883-2890, 1996.

37. Kliffen M, Sharma HS, Mooy CM, Kerkvliet S and de Jong PT: Increased expression of angiogenic growth factors in age-related maculopathy. Br J Ophthalmol 81: 154-162, 1997.

38. Ayalasomayajula SP and Kompella UB: Celecoxib, a selective cyclooxygenase-2 inhibitor, inhibits retinal vascular endothelial growth factor expression and vascular leakage in a streptozotocin-induced diabetic rat model. Eur J Pharmacol 458: 283-289, 2003.

39. Schrufer TL, Antonetti DA, Sonenberg N, Kimball SR, Gardner TW and Jefferson LS: Ablation of 4E-BP1/2 prevents hyperglycemia-mediated induction of VEGF expression in the rodent retina and in Muller cells in culture. Diabetes 59: 2107-2116, 2010

40. Kermorvant-Duchemin E, Sapieha P, Sirinyan M, Beauchamp M, Checchin D, Hardy P, Sennlaub F, Lachapelle P and Chemtob S: Understanding ischemic retinopathies: Emerging concepts from oxygen-induced retinopathy. Doc Ophthalmol 120: 51-60, 2010.

41. Sapieha P, Hamel D, Shao Z, Rivera JC, Zaniolo K, Joyal JS and Chemtob S: Proliferative retinopathies: Angiogenesis that blinds. Int J Biochem Cell Biol 42: 5-12, 2010.
42. Xu L, Kanasaki K, Kitada M and Koya D: Diabetic angiopathy and angiogenic defects. Fibrogenesis Tissue Repair 5: 13, 2012.

43. Zhang J, Wu Y, Jin Y, Ji F, Sinclair SH, Luo Y, Xu G, Lu L, Dai W, Yanoff $\mathrm{M}$, et al: Intravitreal injection of erythropoietin protects both retinal vascular and neuronal cells in early diabetes. Invest Ophthalmol Vis Sci 49: 732-742, 2008.

44. Inai T, Mancuso M, Hashizume H, Baffert F, Haskell A, Baluk P, Hu-Lowe DD, Shalinsky DR, Thurston G, Yancopoulos GD and McDonald DM: Inhibition of vascular endothelial growth factor (VEGF) signaling in cancer causes loss of endothelial fenestrations, regression of tumor vessels, and appearance of basement membrane ghosts. Am J Pathol 165: 35-52, 2004.

45. Shibuya M: Angiogenesis regulated by VEGF and its receptors and its clinical application. Rinsho Ketsueki 50: 404-412, 2009.

46. Adamis AP: Pathological retinal angiogenesis. In: Encyclopedia of the Eye. Darlene AD, Besharse J and Dana R (eds). Academic Press, Oxford, pp280-289, 2010.

47. Campa $\mathrm{C}$ and Harding SP: Anti-VEGF compounds in the treatment of neovascular age related macular degeneration. Curr Drug Targets 12: 173-181, 2011.

48. Chen E, Kaiser RS and Vander JF: Intravitreal bevacizumab for refractory pigment epithelial detachment with occult choroidal neovascularization in age-related macular degeneration. Retina 27: 445-450, 2007

49. Kakkassery V, Winterhalter S and Joussen AM: Anti-VEGF inhibitors and their role in the treatment of diabetic macular oedema. Klin Monbl Augenheilkd 227: 701-711, 2010.

50. Miller JW, Le Couter J, Strauss EC and Ferrara N: Vascular endothelial growth factor a in intraocular vascular disease. Ophthalmology 120: 106-114, 2013.

51. Kern TS: Contributions of inflammatory processes to the development of the early stages of diabetic retinopathy. Exp Diabetes Res 2007: 95103, 2007.

52. Chan PS, Kanwar M and Kowluru RA: Resistance of retinal inflammatory mediators to suppress after reinstitution of good glycemic control: Novel mechanism for metabolic memory. J Diabetes Complications 24: 55-63, 2010.

53. Joussen AM, Poulaki V, Le ML, Koizumi K, Esser C, Janicki H, Schraermeyer U, Kociok N, Fauser S, Kirchhof B, et al: A central role for inflammation in the pathogenesis of diabetic retinopathy. FASEB J 18: 1450-1452, 2004.

54. Tsujikawa A, Ogura Y, Hiroshiba N, Miyamoto K, Kiryu J, Tojo SJ, Miyasaka M and Honda Y: Retinal ischemia-reperfusion injury attenuated by blocking of adhesion molecules of vascular endothelium. Invest Ophthalmol Vis Sci 40: 1183-1190, 1999.

55. Matsubara A, Tomida K, Matsuda Y, Tamai K, Tashita A, Jomori T, Tsujikawa A and Ogura Y: Protective effects of selectin ligands/inhibitor (SKK-60060) against retinal ischemia-reperfusion injury. Exp Eye Res 71: 283-293, 2000.

56. Ueda K, Nakahara T, Hoshino M, Mori A, Sakamoto K and Ishii K: Retinal blood vessels are damaged in a rat model of NMDA-induced retinal degeneration. Neurosci Lett 485: $55-59,2010$

57. Ogata N, Yamanaka R, Yamamoto C, Miyashiro M, Kimoto T, Takahashi K, Maruyama K and Uyama M: Expression of vascular endothelial growth factor and its receptor, KDR, following retinal ischemia-reperfusion injury in the rat. Curr Eye Res 17: 1087-1096, 1998

58. Nishijima K, Ng YS, Zhong L, Bradley J, Schubert W, Jo N, Akita J, Samuelsson SJ, Robinson GS, Adamis AP and Shima DT: Vascular endothelial growth factor-A is a survival factor for retinal neurons and a critical neuroprotectant during the adaptive response to ischemic injury. Am J Pathol 171: 53-67, 2007.

59. Penn JS, Madan A, Caldwell RB, Bartoli M, Caldwell RW and Hartnett ME: Vascular endothelial growth factor in eye disease. Prog Retin Eye Res 27: 331-371, 2008.

60. Guidi AJ, Abu-Jawdeh G, Tognazzi K, Dvorak HF and Brown LF: Expression of vascular permeability factor (vascular endothelial growth factor) and its receptors in endometrial carcinoma. Cancer 78: 454-460, 1996. 